\title{
Stress in biological invasions: Introduced invasive grey squirrels increase physiological stress in native Eurasian red squirrels
}

\author{
Francesca Santicchia ${ }^{1}$ (i) | Ben Dantzer ${ }^{2,3}$ (i) | Freya van Kesteren² (i) | \\ Rupert Palme $^{4}$ (i) | Adriano Martinoli ${ }^{1}$ (D) | Nicola Ferrari ${ }^{5}$ (D) | Lucas Armand Wauters ${ }^{1,6}$ (i)
}

\begin{abstract}
${ }^{1}$ Environment Analysis and Management Unit, Guido Tosi Research Group, Department of Theoretical and Applied Sciences, Università degli Studi dell'Insubria, Varese, Italy; ${ }^{2}$ Department of Psychology, University of Michigan, Ann Arbor, Michigan; ${ }^{3}$ Department of Ecology and Evolutionary Biology, University of Michigan, Ann Arbor, Michigan; ${ }^{4}$ Unit of Physiology, Pathophysiology and Experimental Endocrinology, Department of Biomedical Sciences, University of Veterinary Medicine Vienna, Vienna, Austria; ${ }^{5}$ Department of Veterinary Sciences and Public Health, Università degli Studi di Milano, Milan, Italy and ${ }^{6}$ Department of Biology, Evolutionary Ecology Group, University of Antwerp, Wilrijk, Belgium
\end{abstract}

\section{Correspondence}

Francesca Santicchia, Department of Theoretical and Applied Sciences, Università degli Studi dell'Insubria, via J.H. Dunant 3, 21100 Varese, Italy.

Email: f.santicchia@uninsubria.it

Funding information

ESI (European Squirrel Initiative)

Handling Editor: Blaine Griffen

\section{Abstract}

1. Invasive alien species can cause extinction of native species through processes including predation, interspecific competition for resources or disease-mediated competition. Increases in stress hormones in vertebrates may be associated with these processes and contribute to the decline in survival or reproduction of the native species.

2. Eurasian red squirrels (Sciurus vulgaris) have gone extinct across much of the British Isles and parts of Northern Italy following the introduction of North American invasive grey squirrels (Sciurus carolinensis). We extracted glucocorticoid metabolites from faecal samples to measure whether the presence of the invasive species causes an increase in physiological stress in individuals of the native species.

3. We show that native red squirrels in seven sites where they co-occurred with invasive grey squirrels had glucocorticoid concentrations that were three times higher than those in five sites without the invasive species. Moreover, in a longitudinal study, stress hormones in native red squirrels increased after colonisation by grey squirrels. When we experimentally reduced the abundance of the invasive grey squirrels, the concentration of faecal glucocorticoid metabolites in co-occurring red squirrels decreased significantly between pre- and postremoval periods.

4. Hence, we found that the invasive species acts as a stressor which significantly increases the concentrations of glucocorticoids in the native species.

5. Given that sustained elevations in glucocorticoids could reduce body growth and reproductive rate, our results are consistent with previous studies where the cooccurrence of the invasive grey squirrel was associated with smaller size and lower reproductive output in red squirrels.

\section{KEYWORDS}

biological invasions impact, glucocorticoids, interspecific competition, invasive alien species, physiological stress, removal experiment, Sciurus carolinensis, Sciurus vulgaris 


\section{1 | INTRODUCTION}

The introduction of non-native species that subsequently become invasive (invasive alien species) can cause large economic losses and affect human activities and health (Simberloff et al., 2013). Moreover, invasive species represent a threat to native species world-wide through different ecological processes (Keller, Geist, Jeschke, \& Kühn, 2011), such as interspecific competition (e.g. Cadi \& Joly, 2003; Gurnell, Wauters, Lurz, \& Tosi, 2004), predation (Banks \& Dickman, 2007; Berger, Wikelski, Romero, Kalko, \& Rödl, 2007), transmission of infectious diseases (Daszak, Cunningham, \& Hyatt, 2000) and even changes in ecosystem functioning (Strayer, 2012). Such detrimental effects can lead to extinction of native species and consequent loss of biodiversity (Keller et al., 2011). For example, the introduction of alien species in a new environment can produce high levels of niche overlap with ecologically similar native species, and competition for key resources (Glen \& Dickman, 2008; Mazzamuto, Bisi, Wauters, Preatoni, \& Martinoli, 2017), that can ultimately result in exclusion competition and extinction of the native species (Mooney \& Cleland, 2001).

In vertebrates, interspecific interactions may also impact populations through sublethal individual-level effects (Anson, Dickman, Boonstra, \& Jessop, 2013; Boronow \& Langkilde, 2010) that cause an increase in physiological stress (acute or baseline stress). In fact, vertebrates have a suite of behavioural, hormonal and physiological mechanisms to cope with harmful environmental stimuli (stressors, Romero, 2004). The two most important physiological responses are the stimulation of the sympathetic nervous system (resulting in the release of catecholamines) and the activation of the hypothalamic-pituitary-adrenal (HPA) axis, resulting in the secretion of glucocorticoids (GCS), lasting several minutes to hours, which helps to restore homeostasis (Sapolsky, Romero, \& Munck, 2000). However, while the effects of short-term elevated GC concentrations (acute stress) can help an individual to escape from life-threatening situations (Wingfield et al., 1998), activation of the HPA axis and elevated GC concentrations over a longer period of time (several weeks-months) may have negative effects on body condition, survival or reproductive output (Blas, Bortolotti, Tella, Baos, \& Marchant, 2007; Jessop, Anson, Narayan, \& Lockwood, 2015; Narayan, Jessop, \& Hero, 2015; Sheriff, Krebs, $\&$ Boonstra, 2009). If the stressor persists and GCs remain elevated, alterations of behaviour and/or energy balance, inhibition of growth and/or reproduction (Cabezas, Blas, Marchant, \& Moreno, 2007; Sheriff et al., 2009), increase in blood glucose levels, suppression of digestion (Caso, Leza, \& Menchen, 2008) and suppression of immunity and the inflammatory response (Romero, 2004; St. Juliana, Khokhlova, Wielebnowski, Kotler, \& Krasnov, 2014) can be observed. Competitive food resource exploitation (Chase, Flynn, \& Todgham, 2016), parasite-mediated competition (St. Juliana et al., 2014), introduction of (alien) predators (Anson et al., 2013; Berger et al., 2007) and/or invasive competitors (Boronow \& Langkilde, 2010; Narayan et al., 2015) are all documented cases of direct and/or indirect interspecific interactions that show, through different mechanisms, how negative stimuli lead to increased physiological stress in at least one of the species involved.

In wild mammals, baseline GC concentrations can be estimated using faecal glucocorticoid metabolites, which represent an integrated measure of plasma GCs (FGM concentrations; e.g. Millspaugh \& Washburn, 2004; Sheriff, Dantzer, Delehanty, Palme, \& Boonstra, 2011; Dickens \& Romero, 2013). Hence, measuring these hormones (stress response) in individuals of a native species in situations with and without the invasive species (the environmental stressor) can help us understand if and how the stressor affects animals in native species' populations (Dantzer, Fletcher, Boonstra, \& Sheriff, 2014).

Although there are many studies on the impact of invasive species on native species, only a few have used glucocorticoid metabolites (before and after the stressor) to investigate the degree of physiological impact of invasive predators on native species (frogs, Platymantis vitiana, Narayan, Cockrem, \& Hero, 2013; Narayan et al., 2015; iguanas or lizards, Amblyrhynchus cristatus, Berger et al., 2007; Urosausus ornatus, Graham, Freidenfelds, McCormick, \& Langkilde, 2012; Varanus varius, Anson et al., 2013; Jessop et al., 2015).

Here, we tested the hypothesis that the presence of an invasive species causes an increase in physiological stress in individuals of a native species. We use the well-known case of competitive replacement of the Eurasian red squirrel (Sciurus vulgaris) by the introduced invasive North American grey squirrel (Sciurus carolinensis) in Europe to explore effects of stress at the individual level using faecal glucocorticoid metabolites (FGM; Sheriff et al., 2011; Dantzer et al., 2014, 2016; Haigh, Butler, O'Riordan, \& Palme, 2017). Tree squirrels are often successful invaders (Bertolino, 2009; Di Febbraro, Martinoli, Russo, Preatoni, \& Bertolino, 2016), and the rapid spread of the invasive grey squirrel and subsequent decline and widespread extinction of the native red squirrel on the British Isles and in parts of Italy has been documented in many studies. Both species can produce one to two litters per year between February and June-July (weaned offspring from April to September) with grey squirrels starting earlier than red squirrels in most years (Gurnell et al., 2004). Dispersal of juveniles or subadults occurs mainly in autumn (SeptemberNovember). The two species have similar space use and activity patterns, and compete for food resources, resulting in smaller body size, and reduced female reproduction and juvenile recruitment in red squirrels (Gurnell et al., 2004; Wauters, Gurnell, Martinoli, \& Tosi, 2002; Wauters, Tosi, \& Gurnell, 2002), ultimately causing a decrease in population size and (local) extinction (Bertolino, Montezemolo, Preatoni, Wauters, \& Martinoli, 2014). Food competition is most intense between December and April (Wauters, Gurnell, Martinoli, \& Tosi, 2001; Wauters, Tosi et al., 2002). On the British Isles, a squirrel pox virus results in disease-mediated competition, with grey squirrels acting as a reservoir and transmitting the virus to red squirrels, for which, in most cases, the infection is lethal (McInnes et al., 2013; White et al., 2016). In Italy, the virus is not present (Romeo et al., 2018). 
We first compared FGM concentrations in individual red squirrels co-occurring for more than two years with grey squirrels (red-grey sites), with FGM concentrations of squirrels in sites not colonised by the invasive species (red-only sites), and predicted that FGM concentrations in red squirrels will be higher in red-grey than in red-only sites. However, as the correlative nature of this approach makes it difficult to isolate the invader as the causal factor driving observed differences (Graham, Freidenfelds, Thawley, Robbins, \& Langkilde, 2017), we also tested the direct impact of interactions between invasive and native species. We did this in two ways: (a) monitoring changes in FGM concentrations of red squirrels in two study sites that were colonised by the invader during this study (measuring FGM concentrations before and after colonisation) and comparing them with variation in FGM that occurred over the same time-period in noncolonised red squirrel populations; and (b) removing grey squirrels in red-grey sites over a period of six months, and concomitantly monitoring changes in FGM concentrations in native red squirrels. If the invader causes an increase in FGM concentrations in the native species (i.e. the presence of grey squirrels is the driving factor), we predicted that FGM concentrations will be higher in red squirrels after the two study sites were colonised than before the colonisation by the invasive species (experiment 1); and FGM concentrations in syntopic red squirrels (red-grey sites) will decrease after the removal of the grey squirrels (experiment 2).

\section{2 | MATERIALS AND METHODS}

\section{1 | Study sites}

We trapped Eurasian red squirrels in five study sites without grey squirrels (historically red-only sites) in Lombardy, North Italy (Supporting Information Table S1). Two of these sites (Vanzago, Castelbarco) were colonised by the invasive species during the study; hence, they were used as red-only sites before colonisation (before March 2015 and November 2014, respectively), and as red-grey sites afterwards. We trapped both squirrel species (red-grey sites) in seven study sites in Lombardy and Piedmont, Northern Italy (Supporting Information Table S1). All red-grey sites and the two red-only sites mentioned above (Vanzago and Castelbarco) are lowland mixed deciduous woodlands in the Po plain, while the other three red-only sites (Bormio, Cancano and Valfurva) are subalpine conifer forests in the Central Italian Alps (1,620-2,150 m elevation).

\section{2 | Live-trapping, handling and faecal sample collection}

We trapped squirrels in all sites during trapping sessions that lasted four or five days each (sites and trapping dates listed in Supporting Information Table S1). We used Tomahawk traps (model 202, Tomahawk Live Trap, WI, USA) with a fine mesh added underneath traps to prevent contamination between urine and faeces. We checked traps two to three times a day. Each trapped squirrel was individually marked using numbered metal ear-tags (type $1003 \mathrm{~S}$, National Band and Tag, Newport, KY, USA). We weighed squirrels to the nearest $5 \mathrm{~g}$ using a spring-balance (Pesola AG, Baar, Switzerland) and measured the length of the right hind foot (without nail, $0.5 \mathrm{~mm}$ ) with a ruler (Wauters et al., 2007). A female's reproductive status was defined as nonbreeding (anoestrous, vulva small, no longitudinal opening, not lactating), postoestrous and pregnant (vulva partly or strongly swollen with longitudinal opening, enlarged belly during late pregnancy), or lactating (nipples large, milk excretion can be stimulated). We recorded reproductive condition of males (testes size and position) as nonbreeding (testes abdominal or semi-scrotal and scrotum small) or breeding (testes scrotal and scrotum large). We used the minimum number of animals known to be alive from trapping and observations (MNA, see also Wauters et al., 2008) during each trapping session as an estimate of population size and squirrel density. Previous studies showed that MNA estimates were strongly correlated with estimates from capture-mark-recapture models (e.g. MARK, Wauters et al., 2008).

To test effects of removal of the invasive species on FGM concentrations in co-occurring native red squirrels, we analysed samples from four study sites (Vanzago, Lambro, Passatempo, Castelbarco; see Table 1) where all grey squirrels that were trapped over three subsequent periods (one period every six to ten weeks between November 2015 and May 2016) were removed. If the number of grey squirrels removed in period $i$ is $m_{i}$, then $m_{1}+m_{2}+m_{3}=m_{\text {tot }}$ the total number of grey squirrels removed over the entire experiment. Red squirrel faecal samples collected in period 1 corresponded with high grey squirrel densities $\left(m_{\text {tot }}\right)$, those collected in period 2 with intermediate densities of grey squirrels $\left(m_{2}+m_{3}\right)$, and those collected in period 3 with the lowest grey squirrel densities $\left(m_{3}\right)$ (see Table 1 ). We used $m_{\text {tot }}$ to estimate the minimum number of animals known to be alive (MNA) of the invasive species, considering that no immigration or recruitment of juveniles occurred during the removal period. Trappability of grey squirrels in these relatively small woodlands was high (our unpublished data) and visual observations of individuals of this diurnal and conspicuous species indicated that few animals remained at the end of the removal experiment. Removal of grey squirrels was part of the LIFE09 NAT/IT/000095 EC-SQUARE project: Animals were euthanised by $\mathrm{CO}_{2}$ inhalation, following the EC and AVMA guidelines (Close et al., 1996, 1997; Leary et al., 2013).

After capture and handling, faecal samples were collected from underneath the traps using forceps and placed individually into $1.5-\mathrm{ml}$ vials (Dantzer et al., 2010) and the fine mesh and ground under the traps were cleaned to remove any remaining faecal material. We only used faecal samples from red squirrels that had not previously been trapped or handled within $72 \mathrm{hr}$ prior to capture to minimise effects of capture stress on FGM concentrations (Dantzer et al., 2016). Faecal samples of grey squirrels were also collected (data analysed elsewhere). We obtained multiple samples in different seasons/periods from most 
squirrels, but not all captured individuals produced faeces within a given trapping session. Each faecal sample was classified as being taken in the morning (10.00-13.00 hr) or in the afternoon (15.00-18.00 hr) to account for potential variation in FGM concentration over the $24 \mathrm{hr}$ cycle (Millspaugh \& Washburn, 2004). We placed faecal samples into an insulated bag with ice packs while in the field, and samples were stored at $-20^{\circ} \mathrm{C}$ within $3-4 \mathrm{hr}$ after collection, which should not cause temperature-induced changes in faecal hormone metabolite concentrations (Dantzer et al., 2010). Trapping and handling of squirrels complied with the current laws on animal research in Italy and was carried out with permission of the Region of Lombardy (Decree n. 11190 of 29/11/2013). All of these procedures abided by ASM guidelines (Sikes \& Gannon, 2011).

\subsection{Extraction of hormone metabolites and enzyme immunoassay}

Methods of extraction of FGM and enzyme immunoassay validation for red squirrels and grey squirrels are described in detail elsewhere (Bosson, Palme, \& Boonstra, 2013; Dantzer et al., 2016). Briefly, samples were lyophilised overnight, ground up under liquid nitrogen and weighed to $0.05 \mathrm{~g}( \pm 0.004 \mathrm{~g})$, and extracted using $80 \%$ methanol, shaking at 1,500 r.p.m on a multivortex for $30 \mathrm{~min}$, centrifuging at 2,500 g for $15 \mathrm{~min}$, and aspirating the supernatant. Supernatants were diluted in assay buffer and assayed using a $5 \alpha$-pregnane-3 $\beta, 11 \beta, 21$-triol-20-one enzyme immunoassay (EIA) which detects glucocorticoid metabolites with a $5 \alpha-3 \beta, 11 \beta$-diol structure (for cross-reactivity see Touma, Sachser, Möstl, \& Palme, 2003) to measure FGM concentrations (ng/g dry faeces, Dantzer et al., 2010, 2016). Samples were analysed in duplicate. We assayed 193 faecal samples on a total of 22 EIA plates. Pools of grey squirrel faecal extracts were used as intra-assay controls at dilutions of 1:50 ( 30\% binding) and $1: 400$ ( $70 \%$ binding). Average intra-assay coefficients of variation (CVs) were $9.5 \%$ and $9.4 \%$, respectively, for pools diluted 1:50 and 1:400. Interassay CVs were estimated from standards of known concentration with a high ( $n=22$ plates, $12.3 \%$ binding) and low ( $n=22$ plates, $81.6 \%$ binding) concentration that had interassay CVs of $16.1 \%$ and $9.3 \%$, respectively. To further increase our dataset, we also included 125 samples assayed in a previous study from the same red-only study sites and analysed using the same methodology and in the same laboratory (see Table 1 in Dantzer et al., 2016).

\subsection{Statistical analyses}

All analyses were performed in $\mathrm{R}$ version 3.3.3 ( $\mathrm{R}$ Development Core Team, 2017) using the Ime4 package (version 1.1-12, Bates, Mächler, Bolker, \& Walker, 2015). For each of the models described, we conducted linear mixed-effects models with FGM concentrations (transformed using the natural logarithm, In of $\mathrm{ng} / \mathrm{g}$ dry

TAB LE 1 Data of the grey squirrel removal experiment in four study sites with both squirrel species

\begin{tabular}{|c|c|c|c|c|}
\hline Period & $\begin{array}{l}\text { Red squirrels MNA } \\
\text { (N/ha) }\end{array}$ & $\begin{array}{l}\text { Grey squirrels present } \\
\text { (N/ha) }\end{array}$ & $\begin{array}{l}\text { Grey squirrels } \\
\text { removed }\left(m_{i}\right)(\%)\end{array}$ & $\begin{array}{l}\text { In FGM (ng/g dry faeces) } \\
\text { red squirrels ( } n \text { ) }\end{array}$ \\
\hline \multicolumn{5}{|l|}{ Vanzago (74.73 ha) } \\
\hline Period 2 (March 2016) & $19(0.25)$ & $6(0.08)$ & $5(67)$ & (19) $10.284 \pm 1.051$ \\
\hline Period 3 (May 2016) & $16(0.21)$ & $1(0.01)$ & $1(94)$ & (12) $10.372 \pm 1.176$ \\
\hline Period 1 (November 2015) & $6(0.33)$ & $54(2.93)$ & $24(0)$ & (5) $10.441 \pm 0.467$ \\
\hline Period 2 (December 2015) & $5(0.27)$ & $30(1.63)$ & $11(44)$ & (5) $10.170 \pm 0.942$ \\
\hline Period 3 (March 2016) & $6(0.33)$ & 19 (1.03) & $19(65)$ & (6) $9.321 \pm 0.887$ \\
\hline \multicolumn{5}{|l|}{ Passatempo (18.33 ha) } \\
\hline Period 1 (November 2015) & $9(0.49)$ & $22(1.20)$ & $9(0)$ & (8) $10.958 \pm 1.234$ \\
\hline Period 1 (December 2015) & $21(0.32)$ & $44(0.67)$ & $10(0)$ & (12) $10.361 \pm 0.715$ \\
\hline Period 2 (January 2016) & $19(0.29)$ & $34(0.52)$ & $17(23)$ & (14) $9.922 \pm 0.964$ \\
\hline Period 3 (March 2016) & $25(0.38)$ & $17(0.26)$ & $17(61)$ & (17) $10.392 \pm 0.919$ \\
\hline
\end{tabular}

Notes. Period = capture period with removal (see methods); mean number alive (MNA) of red squirrels (density/ha between brackets); estimated number of grey squirrels present at the start of each removal period (density/ha between brackets); number of grey squirrels removed during each capture period, $m_{i}$, (the cumulative $\%$ grey squirrels removed at the start of the capture period; hence, this is $0 \%$ for Period 1). Ln FGM (ng/g dry faeces) = changes in the concentration of FGM (In FGM, $M \pm S D$, sample size between brackets) over time (period) in red squirrels, following removal of invasive grey squirrels. 
faeces) as the dependent variable and squirrel identity (ID) nested in study site as a random intercept term to account for repeated samples on the same individuals. Sex and reproductive condition nested in sex were added as fixed effects to account for potential changes in FGM concentrations with reproductive activity in males and females (Dantzer et al., 2016; Goymann, 2012). Residuals were visually inspected to verify the assumptions of normality and homoscedasticity (Zuur, leno, \& Elphick, 2010). Where necessary, we assessed significance of pairwise comparisons using differences of least square means (DLSM) with Satterthwaite approximations to degrees of freedom in R package ImerTest (version 2.0-33, Kuznetsova, Brockhoff, \& Christensen, 2016). All full models (see below) contained interactions. When interactions were not significant and including them did not improve model fit ( $\triangle \mathrm{BIC}$ between model with and without interactions >2.0; Schwarz, 1978), they were removed from the models to obtain reliable parameter estimates for the fixed effects.

\subsection{1 | Comparisons between red-only vs. red- grey sites}

We first assessed the direct effects of invasion status (sites with only red squirrels vs. sites with both red and grey squirrels) including also season (winter [December to March], spring-summer [April to August] or autumn [September to November]) and daytime (animal sampled in morning or afternoon) as factors, and body mass as a continuous variable. We also tested the interaction between sex and invasion status to explore whether the effect of the presence of grey squirrels on FGM concentrations in red squirrels differed between the sexes. Study site nested in invasion status was added as random intercept to account for potential differences in FGM concentrations between sites. As sites with only red squirrels occurred in coniferous as well as in deciduous forests, we also explored the effect of habitat type on FGM concentrations (models and results in Supporting Information).

\subsubsection{Effect of colonisation by grey squirrels}

We had two study sites (Vanzago and Castelbarco, $45 \mathrm{~km}$ apart) that were colonised by the invasive species during the study, and we explored whether FGM concentrations in red squirrels changed after the colonisation (samples collected between 6 and 10 months after the precolonisation sample collection, see also Supporting Information Table S1). We also used data from three noncolonised study sites (Valfurva, Bormio and Cancano, see Supporting Information Table S1) that were monitored over the same timeperiod as control data to test whether differences in FGM were simply time-related. We investigated the effects of colonisation (yes or no), time-period (before vs. after, the dates of colonisation) and their interaction, and included sex, reproductive condition nested in sex, daytime, and body mass in the full model. Study site nested in colonisation status was added as a random intercept to account for potential differences in FGM concentrations between sites.

\subsection{3 | Removal experiment}

We assessed the effects of grey squirrel removal considering treatment period (initial sampling when no grey squirrels had been removed yet = period 1 ; intermediate sampling, with a low proportion of grey squirrels removed = period 2; final sampling with a higher proportion of grey squirrels removed = period 3; see methods and Table 1), study site, sex, reproductive condition nested in sex and daytime as factors, and body mass as an explanatory variable, and two factor interactions between the period by study site, and period by sex, to explore whether the removal of grey squirrels would result in a significant decrease in FGM concentrations in sympatric red squirrels. To account for the fact that the observed differences in FGM concentrations between removal periods were influenced by seasonal variation, we also explored a model in which we used season as a fixed effect instead of removal period (both factors could not be fitted in a single model because of problems with collinearity, Zuur et al., 2010). We used the difference in BIC value to test which model best fitted the data (Schwarz, 1978).

\section{3 | RESULTS}

\subsection{FGM concentrations of red squirrels in red- only vs. red-grey sites}

FGM concentrations in native red squirrels (260 samples from 166 different animals) were three times higher in sites that contained invasive grey squirrels ( $n$ samples $=135, M \pm S D=78,133 \pm 61,074 \mathrm{ng} / \mathrm{g}$ dry faeces) than in sites that only contained native red squirrels ( $n=125,24,890 \pm 20,566 \mathrm{ng} / \mathrm{g}$ dry faeces; estimate of the invasion status effect on In FGM: $0.97 \pm 0.20 ; t_{8}=4.85 ; p=0.0012$ ). There

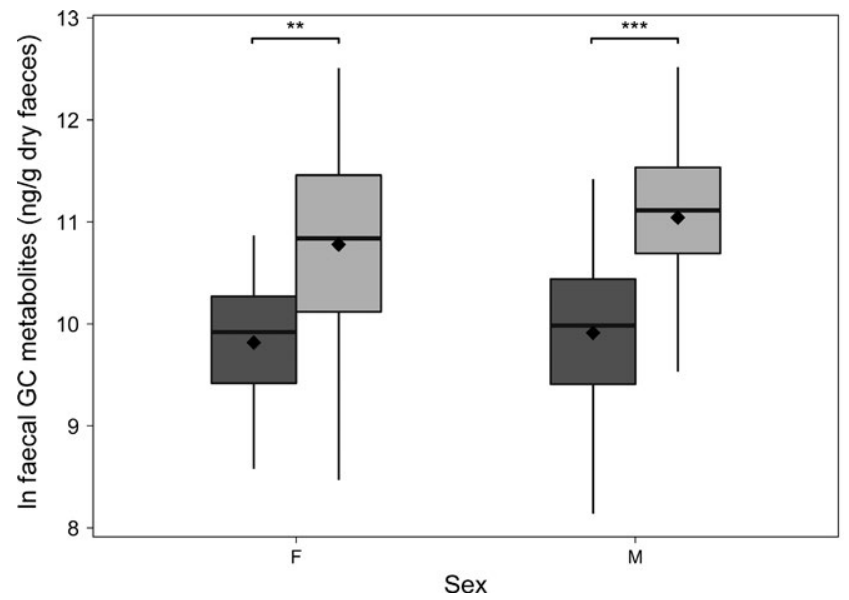

FIGURE 1 Comparison of faecal glucocorticoid (GC) metabolite concentrations in Eurasian red squirrels between red-only (darkgrey colour; 125 samples, 57 females, 68 males) and red-grey (lightgrey colour; 135 samples, 57 females, 78 males) study sites per sex ( $F=$ females; $M=$ males). Boxplots show median (solid horizontal line), mean (black diamond) and 1st (25\%) and 3rd (75\%) quartiles. ${ }^{* *} p<0.01,{ }^{* * *} p<0.001$ 
was no evidence that the presence of invasive grey squirrels impacted the FGM concentrations of the two sexes differently (sex by invasion status interaction: $t_{165}=0.98 ; p=0.33$; Figure 1). FGM concentrations did not differ between the sexes (estimate males against females on In FGM $-0.04 \pm 0.25 ; t_{210}=0.18 ; p=0.86$ ) and were not affected by reproductive condition (males, breeding compared to nonbreeding: $0.06 \pm 0.16 ; t_{247}=0.40 ; p=0.69$; females, pregnant compared to lactating: $-0.12 \pm 0.23 ; t_{249}=0.52 ; p=0.60$; pregnant compared to nonbreeding: $-0.34 \pm 0.23 ; t_{226}=1.50 ; p=0.14$ ). Native red squirrels had lower FGM concentrations in springsummer than in autumn (spring-summer against autumn estimate: $-0.33 \pm 0.14 ; t_{220}=2.39 ; p=0.018$; all other comparisons $p>0.05$ ). FGM concentrations did not vary significantly with daytime (hour of faecal sample collection: $t_{223}=0.76 ; p=0.45$ ) or squirrel body mass $\left(t_{226}=0.30 ; p=0.76\right)$.

\subsection{Effect of colonisation by grey squirrels}

FGM concentrations in red squirrels increased with time-period (before vs. after the dates of colonisation) and with colonisation status (colonised vs. not colonised), and there was a significant time by colonisation status interaction (Supporting Information Table S2). Red squirrels from the three sites without colonisation did not show a significant increase in FGM concentrations between time-periods (difference in In FGM estimate $0.21 \pm 0.15 ; t_{152}=1.27 ; p=0.21$; Figure 2). In contrast, red squirrels in the two sites colonised by the invasive species during our study had a significant increase in FGM from pre- to postcolonisation time-period (difference in In FGM estimate $0.74 \pm 0.18 ; t_{173}=3.93 ; p=0.0004$; Figure 2).

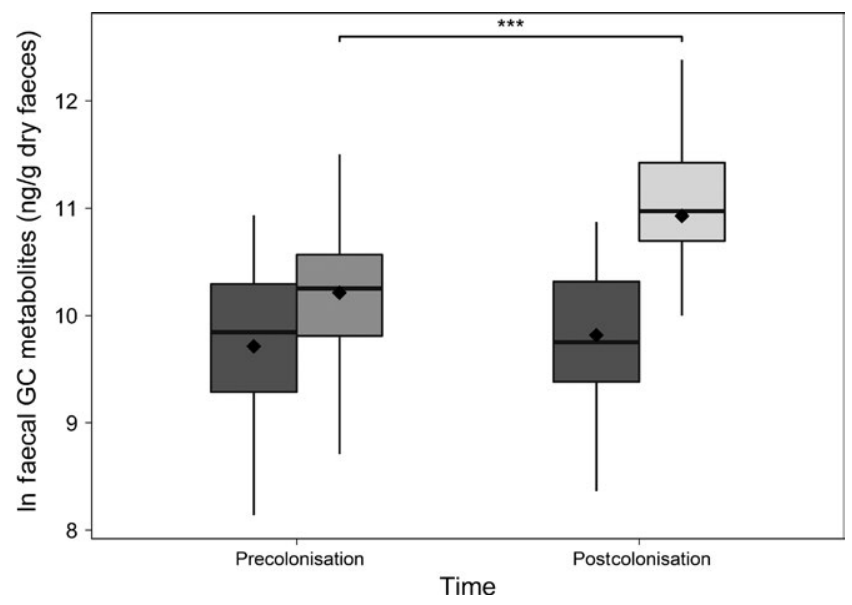

FIGURE 2 Comparison of faecal glucocorticoid (GC) metabolite concentrations in Eurasian red squirrels between precolonisation time and postcolonisation time of sites not colonised by the invasive species (dark-grey colour: precolonisation time, 34 samples; postcolonisation time, 62 samples) and of sites colonised by the grey squirrels over the same time (grey colour: precolonisation time, 29 samples; light-grey colour: postcolonisation time, 58 samples). Boxplots show median (solid horizontal line), mean (black diamond) and 1st (25\%) and 3rd (75\%) quartiles. ${ }^{* * *} p<0.001$
In this dataset, there was no statistically significant effect of sex, reproductive condition nested in sex, daytime or body mass on FGM concentrations (Supporting Information Table S2).

\section{3 | Removal experiment}

After the removal of invasive squirrels, FGM concentrations in cooccurring red squirrels decreased significantly in periods 2 and 3 compared to FGM concentrations at the start of the experiment (period 1, Figure 3 and Table 1). Interactions between period and study site and between period and sex were not significant, and were removed from the model (Supporting Information Table S3). Daytime and body mass also did not influence FGM concentrations and were removed during stepwise model selection (Supporting Information Table S3). FGM concentrations in red squirrels decreased significantly after the first removal session, but there was no further, significant, decrease after the second removal session (period 2-period 1 estimate $-0.58 \pm 0.23, t_{121}=2.53 ; p=0.012$; period 3 -period 1 estimate $-0.50 \pm 0.23, t_{121}=2.18 ; p=0.031$; period 2 -period 3 estimate $0.08 \pm 0.21 ; t_{121}=0.35 ; p=0.73$ ).

There was no difference between FGM concentrations of males and females, but in this dataset, breeding males had higher FGM concentrations than nonbreeding males (Supporting Information Table S3). Variation between study sites was nearly significant only for two sites, with overall lower FGM concentrations in Lambro than in Passatempo (Table 1; difference in In FGM estimate $-0.63 \pm 0.32$; $t_{121}=1.89 ; p=0.06$ ).

The selected model which included 'period' had a lower BIC value than the model which included 'season' $(\triangle B I C=4.53)$, and

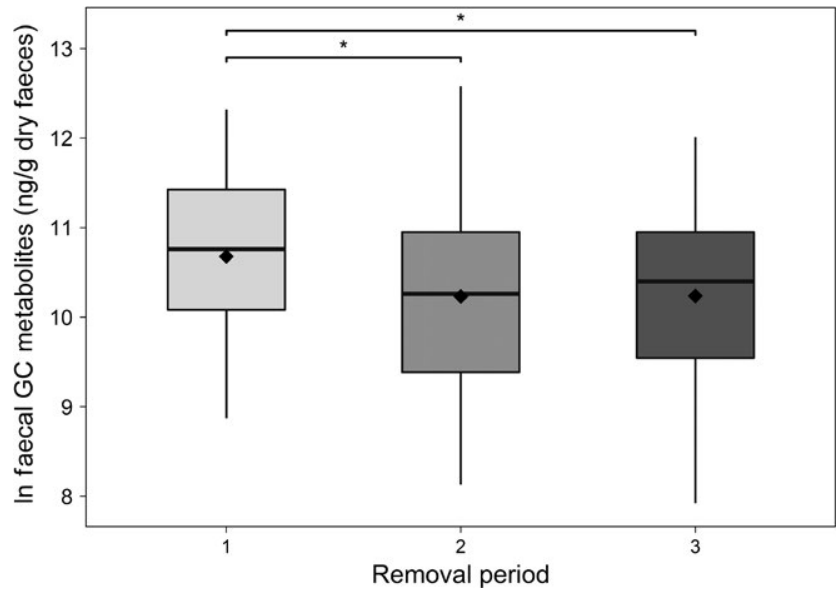

FIGURE 3 Comparison of faecal glucocorticoid (GC) metabolite concentrations in Eurasian red squirrels in trapping period 1 (high grey squirrel density, light-grey colour), period 2 (with lower numbers of grey squirrels, grey colour) and period 3 (low grey squirrel density, dark-grey colour). During the removal experiment, 131 samples of 67 different red squirrels were collected: 38 at the start of removal (period 1), 47 during period 2 and 46 samples during period 3. Boxplots show median (solid horizontal line), mean (black diamond) and 1 st (25\%) and 3rd (75\%) quartiles. ${ }^{*} p<0.05$ 
differences in FGM concentrations between seasons were not statistically significant (all $p>0.10$ ).

\section{4 | DISCUSSION}

We assessed the impact of an invasive alien competitor on faecal glucocorticoid metabolite concentrations in individuals of a native species. We predicted that the threat posed by invasive grey squirrels would increase FGM concentrations in co-occurring native red squirrels. FGM concentrations were significantly higher in sites invaded by grey squirrels than in red-only sites, and in the two areas colonised by grey squirrels during our study, FGM concentrations in the native red squirrels increased with respect to precolonisation concentrations. Both results support our hypothesis and suggest that the invader is the causal factor driving observed differences in FGM concentrations (see also Graham et al., 2017). This was further supported by our grey squirrel removal experiment. Removal of grey squirrels resulted in a significant decrease in glucocorticoids in co-occurring red squirrels over a two month interval, taking into account seasonal variation in glucocorticoid concentrations and changes in reproductive condition in both males and females (see also Boonstra, Hubbs, Lacey, \& McColl, 2001; Dantzer et al., 2010). The reduction in glucocorticoids was more pronounced in two sites: These were the two smallest woodlands that, at the start of the experiment, had the highest grey squirrel densities (Passatempo and Lambro, Table 1) and where red squirrel home ranges were more strongly overlapped by individuals of the invasive species (L. A. Wauters, unpublished data 2016).

\subsection{Comparisons between red-only vs. red- grey sites}

Native red squirrels had higher FGM concentrations in areas where they co-occurred with the invasive grey squirrels than did those in areas without the introduced competitor. This pattern is supported by previous studies. Stress levels of native lizards (Sceloporus undulatus) were higher in sites with a long history of co-occurrence with invasive fire ants (Solenopsis invicta) than in sites without the invader (Graham et al., 2012). Similar results were found in a system of a native lizard (the lace monitor, Varanus varius) and an introduced alien predator (red fox, Vulpes vulpes) in Australia. In habitats with high fox densities, lizards produced a significantly greater basal and capture stress-induced corticosterone response compared to individuals in low-fox density habitat, suggesting competition with red foxes, perhaps via nutritional stress and increased hypersensitivity of the adrenocortical axis in lizards (Jessop et al., 2015). So far, it is not clear whether such responses mediate lizard fitness. Another study examined whether introduced foxes caused elevated glucocorticoid (GC) hormone concentrations (predator stress hypothesis) on a native predator (Varanus varius) and a prey species (ringtail possum, Pseudocheirus peregrinus). No differences were found in glucocorticoid concentrations or in haemoparasite loads between areas with and without fox control in either of the two native species (Anson et al., 2013). These types of observational studies reveal the need for experimental manipulations to investigate the potential causality of the relationship between the presence of invasive species and increased stress in native species.

\section{2 | Pre - postcolonisation}

The colonisation by grey squirrels in two of our study sites can be considered as a natural experiment of introducing an invasive competitor. The strong increase in FGM concentrations we detected following colonisation of grey squirrels suggests that grey squirrels are causing the higher levels of physiological stress detected in field samples from the native species. Extra support to this interpretation is given by the fact that no such increase occurred in red squirrels monitored over the same time-period in sites that were not colonised. A similar pattern was documented in the only study we found which used experimental approaches to investigate changes in stress levels in the native and endangered Fijian ground frog (Platymantis vitiana) caused by the presence of introduced cane toads (Rhinella marina) that can prey on the native frogs (Narayan et al., 2013, 2015). Artificial exposure or introduction of the alien predator resulted in an increase in urinary corticosterone metabolites (Narayan et al., 2013) and subsequently reduced reproductive success (fewer eggs laid in enclosures which also contained alien predators than in nopredator enclosures) in the endemic species (Narayan et al., 2015).

\subsection{The removal experiment}

A next step is manipulation of the presence/density of the invasive species that acts as stressor. Previous studies used an approach where they compared areas without predator manipulation to areas with predator manipulation (e.g. Anson et al., 2013; Jessop et al., 2015). We used a new approach: removal over time comparing the observed changes in faecal glucocorticoid metabolites within populations using sites as independent replicates. In other words, the FGM concentrations in individual red squirrels within a given population/study site are measured under high pressure of grey squirrels (no removal) and compared with lower pressure of the invasive species (after removal). This experiment may be confounded by temporal effects on glucocorticoids, such as the season effect found in the data comparing redonly with red-grey sites, and the time span from the beginning of the removal and the measurements. However, our models showed that seasonal variation in FGM measures was not statistically significant in this dataset and that models with removal period better fitted the data than models including a season effect. Moreover, the strongest decrease in FGM concentrations of red squirrels after removal of grey squirrels occurred between period 1 and period 2. FGM data for period 1 were gathered in autumn and winter, and all data for period 2 were taken in winter, and in the large dataset comparing red-only with red-grey sites, there was no significant difference between winter and autumn levels of glucocorticoids. In a dataset of red squirrels in areas without the invasive species, glucocorticoids were even higher in winter than in autumn (Dantzer et al., 2016). Hence, these 
data support our conclusion that the observed decrease in faecal glucocorticoid metabolites in red squirrels was indeed caused by a reduction of the density of invasive grey squirrels.

We found that FGM concentrations in native red squirrels decreased significantly (between the first and second period) in relation to invasive species removal. FGM levels also remained lower in the third period (see Figure 3), but a further decrease with respect to period 2 was observed only in the two smallest study sites, where, as mentioned above, grey squirrels occurred at the highest densities when the experiment started (see Table 1).This suggests that the impact of the invasive competitor on individual red squirrels' FGM concentrations is probably related to the degree of home range (or core-area) overlap, and the resulting differences in food competition and pilfering of red squirrel caches by overlapping greys (Wauters \& Gurnell, 1999; Wauters, Tosi et al., 2002). In fact, in areas of co-occurrence there is no niche partitioning between the two species (Wauters, Gurnell et al., 2002), in marked contrast with the habitat specialisation and niche differentiation observed between coevolved North American red squirrels and grey squirrels in mixed forests in their natural range (Riege, 1991). Although shifts in diet may be a possible driver of changes in FGM concentration (Dantzer, McAdam, Palme, Boutin, \& Boonstra, 2011; Goymann, 2012), we believe it is unlikely that this is the main driver in our study for several reasons. First, we controlled for habitat effects and still found higher FGM concentrations in red squirrels in deciduous woods with grey squirrels than in similar habitats without the invasive species. Second, the experimental approaches (colonisation and removal) were within-site comparisons. Third, we believe it is unlikely that within a study area, FGM increases in red squirrels were driven by red squirrels foraging on poorer quality food items due to food competition with grey squirrels because grey squirrel densities were relatively low in our study sites. Furthermore, previous studies showed high foraging niche overlap between the two species in red-grey sites which, however, did not result in diet shifts and/or lower daily energy-intake in red squirrels during most of the year (see Wauters et al., 2001; Wauters, Gurnell et al., 2002). Finally, it is unlikely that increased hormonal stress in native red squirrels is caused by direct (aggressive) interactions with grey squirrels, as interspecific interactions are rare and much less common than intraspecific aggression (Wauters \& Gurnell, 1999).

\section{4 | Physiological relevance and fitness consequences}

Here, we documented a threefold increase in FGMs in red squirrels in red-grey sites compared to red-only sites, a twofold increase in sites that were colonised by the invasive species and a 1.5-fold decrease when grey squirrels were removed. Although it may be difficult to assess the direct physiological relevance of increased FGM (Dickens \& Romero, 2013), and comparisons between studies are complicated due to the use of different experimental protocols (e.g. Fanson et al., 2017) and other variables that may affect FGM concentrations (Dantzer et al., 2011; Goymann, 2012), we believe that the changes in FGMs that we observed are comparable to chronic stress paradigms found in other studies and that they may have other effects on life-history traits. For example, in a communally breeding rodent (Ctenomys sociabilis) the difference in baseline glucocorticoid levels between animals kept in less or more stressful situations was about 1.5-fold to twofold (Woodruff, Lacey, Bentley, \& Kriegsfeld, 2013). A previous study in wild North American red squirrels (Tamiasciurus hudsonicus) showed that pregnant females have 30\% higher FGMs when high population density conditions were simulated and that this was associated with a change in offspring postnatal growth rates (Dantzer et al., 2013). Laboratory studies have found similar effects, and, in laboratory rats, exposure to a variable chronic stress paradigm caused a $~ 1.5$-fold increase in plasma corticosterone levels (Herman, Adams, \& Prewitt, 1995).

To date, few studies have been able to demonstrate the consequences of prolonged elevations of glucocorticoids caused by invasive species on native species' fitness components (Narayan et al., 2015). Our study was too short to reveal fitness consequences of the increase in glucocorticoids levels in red squirrels in areas invaded by the congener. However, our previous studies clearly demonstrated negative effects of grey squirrels, exacerbated at high densities of the invasive species, on red squirrel body size and reproductive rate (Gurnell et al., 2004; Wauters et al., 2001). Both these effects are in agreement with alterations of the hormonal functions of glucocorticoids in regulating of body growth and reproduction (Cabezas et al., 2007; Sheriff et al., 2009). Therefore, we conclude that invasive grey squirrels increase FGM concentrations in native red squirrels and this increase in glucocorticoids is likely to have physiological impacts on red squirrels, such as affecting growth and reproduction (Dantzer et al., 2013; Gurnell, Lurz, \& Wauters, 2015; Wauters et al., 2001). Moreover, studies on animal models indicate that chronic stress can reduce immune efficiency (Sapolsky et al., 2000), and further research will explore whether this mechanism is involved in the probability that naïve red squirrels acquire an alien parasite, Strongyloides robustus, typical of grey squirrels (Romeo et al., 2015).

The interaction between invasive and native species is a phenomenon that occurs through many different mechanisms (e.g. direct competition, parasite-mediated competition, disease transmission, predation, habitat destruction or alteration) in a wide variety of ecosystems. This study shows that direct and/or indirect effects of increases in physiological stress in native species caused by the presence of an invasive species should be considered as one of these mechanisms. Our FGM data suggest that red squirrels are chronically stressed by invasive grey squirrels. Although there are wild species in which chronic stress may be an evolutionary response to stressors such as predation pressure and is not necessarily deleterious, (see Boonstra, 2013), we believe this is not the case in our study system. Our results indicate that red squirrels have a physiological stress response to a threat posed by an invasive competitor to which they show no evolutionary adaptation. Therefore, the observed increase in glucocorticoid concentrations is likely to have detrimental consequences for red squirrels (Gurnell et al., 2004, 2015; Romeo et al., 2015; Wauters et al., 2001). We suggest that future studies 
should assess whether and how changes in stress levels are involved in species interactions and invasion processes and to what extent it has direct or indirect (e.g. by increasing susceptibility to parasite infections) fitness consequences for the native species.

\section{ACKNOWLEDGEMENTS}

Thanks to Zainab Almusawi for helping in laboratory analysis, Mattia Panzeri and Greta Colombo for assistance with the fieldwork. We thank Stelvio National Park to allow research in three study areas and to natural reserve-sic/zps "Bosco WWF di Vanzago" for access to the woodlands and housing facilities. We are also grateful to the private land owners for access to their estates. Constructive comments by two anonymous reviewers and by the associate editor greatly helped us to improve the manuscript. This is Paper no. 29 of the ASPER (Alpine Squirrel Population Ecology Research) project. ESI (European Squirrel Initiative) funded laboratory analyses.

\section{AUTHORS' CONTRIBUTIONS}

This study is part of F.S. PhD project supervised by A.M. F.S., L.A.W. and N.F. designed the study and analyses. Fieldwork and data collection were carried out by F.S. and L.A.W. F.S. and F.v.K. carried out laboratory analyses, and B.D. supplied laboratory space and equipment, and coordinated laboratory analyses. R.P. produced and supplied reagents for laboratory analyses. F.S. carried out statistical analyses with the contribution of B.D. and N.F. The manuscript was written by F.S. and L.A.W. with improvement and editorial input from all other authors. All authors gave approval for publication.

\section{DATA ACCESSIBILITY}

Data available from the Dryad Digital Repository: https://doi. org/10.5061/dryad.bp8jf84 (Santicchia et al., 2018).

\section{ORCID}

Francesca Santicchia iD http://orcid.org/0000-0003-4814-9632

Ben Dantzer (iD http://orcid.org/0000-0002-3058-265X

Freya van Kesteren (iD http://orcid.org/0000-0002-3034-9022

Rupert Palme iD http://orcid.org/0000-0001-9466-3662

Adriano Martinoli iD http://orcid.org/0000-0003-0298-0869

Nicola Ferrari (iD http://orcid.org/0000-0001-8959-3495

Lucas Armand Wauters (iD http://orcid.org/0000-0002-4871-5035

\section{REFERENCES}

Anson, J. R., Dickman, C. R., Boonstra, R., \& Jessop, T. S. (2013). Stress triangle: Do introduced predators exert indirect costs on native predators and prey? PLoS ONE, 8, e60916. https://doi.org/10.1371/ journal.pone.0060916
Banks, P. B., \& Dickman, C. R. (2007). Alien predation and the effects of multiple levels of prey naiveté. Trends in Ecology \& Evolution, 22, 229-230. https://doi.org/10.1016/j.tree.2007.02.006

Bates, D., Mächler, M., Bolker, B., \& Walker, S. (2015). Fitting linear mixed-effects models using Ime4. Journal of Statistical Software, 67. https://doi.org/10.18637/jss.v067.i01

Berger, S., Wikelski, M., Romero, L. M., Kalko, E. K. V., \& Rödl, T. (2007). Behavioral and physiological adjustments to new predators in an endemic island species, the Galápagos marine iguana. Hormones and Behavior, 52, 653-663. https://doi.org/10.1016/ j.yhbeh.2007.08.004

Bertolino, S. (2009). Animal trade and non-indigenous species introduction: The world-wide spread of squirrels. Diversity and Distributions, 15, 701-708. https://doi.org/10.1111/j.1472-4642.2009.00574.x

Bertolino, S., Montezemolo, N. C., Preatoni, D. G., Wauters, L. A., \& Martinoli, A. (2014). A grey future for Europe: Sciurus carolinensis is replacing native red squirrels in Italy. Biological Invasions, 16, 53-62. https://doi.org/10.1007/s10530-013-0502-3

Blas, J., Bortolotti, G. R., Tella, J. L., Baos, R., \& Marchant, T. A. (2007). Stress response during development predicts fitness in a wild, long lived vertebrate. Proceedings of the National Academy of Sciences USA, 104, 8880-8884. https://doi.org/10.1073/pnas.0700232104

Boonstra, R. (2013). Reality as the leading cause of stress: Rethinking the impact of chronic stress in nature. Functional Ecology, 27, 11-23. https://doi.org/10.1111/1365-2435.12008

Boonstra, R., Hubbs, A. H., Lacey, E. A., \& McColl, C. J. (2001). Seasonal changes in glucocorticoid and testosterone concentrations in free-living arctic ground squirrels from the boreal forest of the Yukon. Canadian Journal of Zoology, 79, 49-58. https://doi.org/10.1139/z00-175

Boronow, K. E., \& Langkilde, T. (2010). Sublethal effects of invasive fire ant venom on a native lizard. Journal of Experimental Zoology Part A: Ecological and Integrative Physiology, 313A, 17-23. https://doi. org/10.1002/jez.570

Bosson, C. O., Palme, R., \& Boonstra, R. (2013). Assessing the impact of live-capture, confinement, and translocation on stress and fate in eastern gray squirrels. Journal of Mammalogy, 94, 1401-1411. https:// doi.org/10.1644/13-MAMM-A-046.1

Cabezas, S., Blas, J., Marchant, T. A., \& Moreno, S. (2007). Physiological stress levels predict survival probabilities in wild rabbits. Hormones and Behavior, 51, 313-320. https://doi.org/10.1016/ j.yhbeh.2006.11.004

Cadi, A., \& Joly, P. (2003). Competition for basking places between the endangered European pond turtle (Emys orbicularis galloitalica) and the introduced red-eared slider (Trachemys scripta elegans). Canadian Journal of Zoology, 81, 1392-1398. https://doi.org/10.1139/z03-108

Caso, J. R., Leza, J. C., \& Menchen, L. (2008). The effects of physical and psychological stress on the gastrointestinal tract: Lessons from animal models. Current Molecular Medicine, 8, 299-312. https://doi. org/10.2174/156652408784533751

Chase, D. A., Flynn, E. E., \& Todgham, A. E. (2016). Survival, growth and stress response of juvenile tidewater goby, Eucyclogobius newberryi, to interspecific competition for food. Conservation Physiology, 4 cow013. https://doi.org/10.1093/conphys/cow013

Close, B., Banister, K., Baumans, V., Bernoth, E.-M., Bromage, N., Bunyan, J., ... Warwick, C. (1996). Recommendations for euthanasia of experimental animals: Part 1. Laboratory Animals, 30, 293-316. https://doi. org/10.1258/002367796780739871

Close, B., Banister, K., Baumans, V., Bernoth, E.-M., Bromage, N., Bunyan, J., ... Warwick, C. (1997). Recommendations for euthanasia of experimental animals: Part 2. Laboratory Animals, 31, 1-32. https://doi. org/10.1258/002367797780600297

Dantzer, B., Fletcher, Q. E., Boonstra, R., \& Sheriff, M. J. (2014). Measures of physiological stress: A transparent or opaque window into the status, management and conservation of species? Conservation Physiology, 2, cou023. https://doi.org/10.1093/conphys/cou023 
Dantzer, B., McAdam, A. G., Palme, R., Boutin, S., \& Boonstra, R. (2011). How does diet affect fecal steroid hormone metabolite concentrations? An experimental examination in red squirrels. General and Comparative Endocrinology, 174, 124-131. https://doi.org/10.1016/ j.ygcen.2011.08.010

Dantzer, B., McAdam, A. G., Palme, R., Fletcher, Q. E., Boutin, S., Humphries, M. M., \& Boonstra, R. (2010). Fecal cortisol metabolite levels in free-ranging North American red squirrels: Assay validation and the effects of reproductive condition. General and Comparative Endocrinology, 167, 279-286. https://doi.org/10.1016/ j.ygcen.2010.03.024

Dantzer, B., Newman, A. E. M., Boonstra, R., Palme, R., Boutin, S., Humphries, M. M., \& McAdam, A. G. (2013). Density triggers maternal hormones that increase adaptive offspring growth in a wild mammal. Science, 340, 1215-1217. https://doi.org/10.1126/science.1235765

Dantzer, B., Santicchia, F., van Kesteren, F., Palme, R., Martinoli, A., \& Wauters, L. A. (2016). Measurement of fecal glucocorticoid metabolite levels in Eurasian red squirrels (Sciurus vulgaris): Effects of captivity, sex, reproductive condition, and season. Journal of Mammalogy, 97, 1385-1398. https://doi.org/10.1093/jmammal/gyw095

Daszak, P., Cunningham, A. A., \& Hyatt, A. D. (2000). Emerging infectious diseases of wildlife-threats to biodiversity and human health. Science, 287, 443-449. https://doi.org/10.1126/science.287.5452.443

Di Febbraro, M., Martinoli, A., Russo, D., Preatoni, D., \& Bertolino, S. (2016). Modelling the effects of climate change on the risk of invasion by alien squirrels. Hystrix, the Italian Journal of Mammalogy, 27, 22-29. https://doi.org/10.4404/hystrix-27.1-11776

Dickens, M. J., \& Romero, M. L. (2013). A consensus endocrine profile for chronically stressed wild animals does not exist. General and Comparative Endocrinology, 191, 177-189. https://doi.org/10.1016/ j.ygcen.2013.06.014

Fanson, K. V., Best, E. C., Bunce, A., Fanson, B. G., Hogan, L. A., Keeley, T., ... Bashaw, M. (2017). One size does not fit all: Monitoring faecal glucocorticoid metabolites in marsupials. General and Comparative Endocrinology, 244, 146-156. https://doi.org/10.1016/ j.ygcen.2015.10.011

Glen, A. S., \& Dickman, C. R. (2008). Niche overlap between marsupial and eutherian carnivores: Does competition threaten the endangered spotted-tailed quoll? Journal of Applied Ecology, 45, 700-707. https://doi.org/10.1111/j.1365-2664.2007.01449.x

Goymann, W. (2012). On the use of non-invasive hormone research in uncontrolled, natural environments: The problem with sex, diet, metabolic rate and the individual. Methods in Ecology and Evolution, 3, 757-765. https://doi.org/10.1111/j.2041-210X.2012.00203.x

Graham, S. P., Freidenfelds, N. A., McCormick, G. L., \& Langkilde, T. (2012). The impacts of invaders: Basal and acute stress glucocorticoid profiles and immune function in native lizards threatened by invasive ants. General and Comparative Endocrinology, 176, 400-408. https://doi.org/10.1016/j.ygcen.2011.12.027

Graham, S. P., Freidenfelds, N. A., Thawley, C. J., Robbins, T. R., \& Langkilde, T. (2017). Are invasive species stressful? The glucocorticoid profile of native lizards exposed to invasive fire ants depends on the context. Physiological and Biochemical Zoology, 90, 328-337. https://doi.org/10.1086/689983

Gurnell, J., Lurz, P. W. W., \& Wauters, L. A. (2015). Years of interactions and conflict in Europe: Competition between Eurasian red squirrels and North American grey squirrel. In C. M. Shuttleworth, P. W. W. Lurz, \& M. W. Hayward (Eds.), Red squirrels: Ecology, conservation \& management in Europe (pp. 19-37). Woodbridge, UK: European Squirrel Initiative.

Gurnell, J., Wauters, L. A., Lurz, P. W., \& Tosi, G. (2004). Alien species and interspecific competition: Effects of introduced eastern grey squirrels on red squirrel population dynamics. Journal of Animal Ecology, 73, 26-35. https://doi.org/10.1111/j.1365-2656.2004.00791.x
Haigh, A., Butler, F., O'Riordan, R., \& Palme, R. (2017). Managed parks as a refuge for the threatened red squirrel (Sciurus vulgaris) in light of human disturbance. Biological Conservation, 211, 29-36. https://doi. org/10.1016/j.biocon.2017.05.008

Herman, J. P., Adams, D., \& Prewitt, C. (1995). Regulatory changes in neuroendocrine stress-integrative circuitry produced by a variable stress paradigm. Endocrinology, 61, 180-190. https://doi. org/10.1159/000126839

Jessop, T. S., Anson, J. R., Narayan, E., \& Lockwood, T. (2015). An introduced competitor elevates corticosterone responses of a native lizard (Varanus varius). Physiological and Biochemical Zoology, 88, 237245. https://doi.org/10.1086/680689

Keller, R. P., Geist, J., Jeschke, J. M., \& Kühn, I. (2011). Invasive species in Europe: Ecology, status, and policy. Environmental Sciences Europe, 23, 23. https://doi.org/10.1186/2190-4715-23-23

Kuznetsova, A., Brockhoff, P. B., \& Christensen, R. H. B. (2016). ImerTest: Tests in linear mixed effects models. R package version 2.0-33. https:// CRAN.R-project.org/package=ImerTest

Leary, S., Underwood, W., Anthony, R., Cartner, S., Corey, D., Grandin, T., ... Yanong, R. (2013). AVMA guidelines for the euthanasia of animals: 2013 edition. Schaumburg, IL: American Veterinary Medical Association.

Mazzamuto, M. V., Bisi, F., Wauters, L. A., Preatoni, D. G., \& Martinoli, A. (2017). Interspecific competition between alien Pallas's squirrels and Eurasian red squirrels reduces density of the native species. Biological Invasions, 19, 723-735. https://doi.org/10.1007/s10530-016-1310-3

Mclnnes, C. J., Coulter, L., Dagleish, M. P., Deane, D., Gilray, J., Percival, A., ... Sainsbury, A. W. (2013). The emergence of squirrelpox in Ireland. Animal Conservation, 16, 51-59. https://doi. org/10.1111/j.1469-1795.2012.00570.x

Millspaugh, J. J., \& Washburn, B. E. (2004). Use of fecal glucocorticoid metabolite measures in conservation biology research: Considerations for application and interpretation. General and Comparative Endocrinology, 138, 189-199. https://doi.org/10.1016/ j.ygcen.2004.07.002

Mooney, H. A., \& Cleland, E. E. (2001). The evolutionary impact of invasive species. Proceedings of the National Academy of Sciences USA, 98, 5446-5451. https://doi.org/10.1073/pnas.091093398

Narayan, E. J., Cockrem, J. F., \& Hero, J.-M. (2013). Sight of a predator induces a corticosterone stress response and generates fear in an amphibian. PLoS ONE, 8, e73564. https://doi.org/10.1371/journal. pone.0073564

Narayan, E. J., Jessop, T. S., \& Hero, J.-M. (2015). Invasive cane toad triggers chronic physiological stress and decreased reproductive success in an island endemic. Functional Ecology, 29, 1435-1444. https://doi. org/10.1111/1365-2435.12446

R Core Team (2017). R: A language and environment for statistical computing. Vienna, Austria: R Foundation for Statistical Computing. https:// www.R-project.org/

Riege, D. A. (1991). Habitat specialization and social factors in distribution of red and gray squirrels. Journal of Mammalogy, 72, 152-162. https://doi.org/10.2307/1381990

Romeo, C., Ferrari, N., Lanfranchi, P., Saino, N., Santicchia, F., Martinoli, A., $\&$ Wauters, L. A. (2015). Biodiversity threats from outside to inside: Effects of alien grey squirrel (Sciurus carolinensis) on helminth community of native red squirrel (Sciurus vulgaris). Parasitology Research, 114, 2621-2628. https://doi.org/10.1007/s00436-015-4466-3

Romeo, C., Mclnnes, C. J., Dale, T. D., Shuttleworth, C. M., Bertolino, S., Wauters, L. A., \& Ferrari, N. (2018). Disease, invasions and conservation: No evidence of squirrelpox virus in grey squirrels introduced to Italy. Animal Conservation. https://doi.org/10.1111/acv.12433

Romero, L. M. (2004). Physiological stress in ecology: Lessons from biomedical research. Trends in Ecology \& Evolution, 19, 249-255. https:// doi.org/10.1016/j.tree.2004.03.008 
Santicchia, F., Dantzer, B., van Kesteren, F., Palme, R., Martinoli, A. Ferrari, N., \& Wauters, L. A. (2018). Data from: Stress in biological invasions: Introduced invasive grey squirrels increase physiological stress in native Eurasian red squirrels. Dryad Digital Repository, https://doi.org/10.5061/dryad.bp8jf84

Sapolsky, R. M., Romero, L. M., \& Munck, A. U. (2000). How do glucocorticoids influence stress responses? Integrating permissive, suppressive, stimulatory, and preparative actions. Endocrine Reviews, 21, 55-89. https://doi.org/10.1210/edrv.21.1.0389

Schwarz, G. E. (1978). Estimating the dimension of a model. Annals of Statistics, 6, 461-464. https://doi.org/10.1214/aos/1176344136

Sheriff, M. J., Dantzer, B., Delehanty, B., Palme, R., \& Boonstra, R. (2011). Measuring stress in wildlife: Techniques for quantifying glucocorticoids. Oecologia, 166, 869-887. https://doi.org/10.1007/ s00442-011-1943-y

Sheriff, M. J., Krebs, C. J., \& Boonstra, R. (2009). The sensitive hare: Sublethal effects of predator stress on reproduction in snowshoe hares. Journal of Animal Ecology, 78, 1249-1258. https://doi. org/10.1111/j.1365-2656.2009.01552.x

Sikes, R. S., \& Gannon, W. L. (2011). Guidelines of the American Society of Mammalogists for the use of wild mammals in research. Journal of Mammalogy, 92, 235-253. https://doi. org/10.1644/10-MAMM-F-355.1

Simberloff, D., Martin, J.-L., Genovesi, P., Maris, V., Wardle, D. A., Aronson, J., ... Vilà, M. (2013). Impacts of biological invasions: What's what and the way forward. Trends in Ecology \& Evolution, 28, 58-66. https://doi.org/10.1016/j.tree.2012.07.013

St. Juliana, J. R., Khokhlova, I. S., Wielebnowski, N., Kotler, B. P., \& Krasnov, B. R. (2014). Ectoparasitism and stress hormones: Strategy of host exploitation, common host-parasite history and energetics matter. Journal of Animal Ecology, 83, 1113-1123. https://doi. org/10.1111/1365-2656.12217

Strayer, D. L. (2012). Eight questions about invasions and ecosystem functioning. Ecology Letters, 15, 1199-1210. https://doi. org/10.1111/j.1461-0248.2012.01817.x

Touma, C., Sachser, N., Möstl, E., \& Palme, R. (2003). Effects of sex and time of day on metabolism and excretion of corticosterone in urine and feces of mice. General and Comparative Endocrinology, 130, 267278. https://doi.org/10.1016/S0016-6480(02)00620-2

Wauters, L. A., Githiru, M., Bertolino, S., Molinari, A., Tosi, G., \& Lens, L. (2008). Demography of alpine red squirrel populations in relation to fluctuations in seed crop size. Ecography, 31, 104-114. https://doi. org/10.1111/j.2007.0906-7590.05251.x

Wauters, L. A., \& Gurnell, J. (1999). The mechanism of replacement of red squirrels by grey squirrels: $A$ test of the interference competition hypothesis. Ethology, 105, 1053-1071. https://doi. org/10.1046/j.1439-0310.1999.10512488.x

Wauters, L., Gurnell, J., Martinoli, A., \& Tosi, G. (2001). Does interspecific competition with introduced grey squirrels affect foraging and food choice of Eurasian red squirrels? Animal Behaviour, 61, 1079-1091. https://doi.org/10.1006/anbe.2001.1703
Wauters, L., Gurnell, J., Martinoli, A., \& Tosi, G. (2002). Interspecific competition between native Eurasian red squirrels and alien grey squirrels: Does resource partitioning occur? Behavioral Ecology and Sociobiology, 52, 332-341. https://doi.org/10.1007/s00265-002-0516-9

Wauters, L., Tosi, G., \& Gurnell, J. (2002). Interspecific competition in tree squirrels: Do introduced grey squirrels (Sciurus carolinensis) deplete tree seeds hoarded by red squirrels (S. vulgaris)? Behavioral Ecology and Sociobiology, 51, 360-367. https://doi.org/10.1007/ s00265-001-0446-y

Wauters, L. A., Vermeulen, M., Van Dongen, S., Bertolino, S., Molinari, A., Tosi, G., \& Matthysen, E. (2007). Effects of spatio-temporal variation in food supply on red squirrel Sciurus vulgaris body size and body mass and its consequences for some fitness components. Ecography, 30, 51-65. https://doi.org/10.1111/j.0906-7590.2007.04646.x

White, A., Lurz, P., Bryce, J., Tonkin, M., Ramoo, K., Bamforth, L., ... Boots, M. (2016). Modelling disease spread in real landscapes: Squirrelpox spread in Southern Scotland as a case study. Hystrix, the Italian Journal of Mammalogy, 27, 75-82. https://doi.org/10.4404/ hystrix-27.1-11657

Wingfield, J. C., Maney, D. L., Breuner, C. W., Jacobs, J. D., Lynn, S., Ramenofsky, M., \& Richardson, R. D. (1998). Ecological bases of hormone-behavior interactions: The "emergency life history stage". Integrative and Comparative Biology, 38, 191-206. https://doi. org/10.1093/icb/38.1.191

Woodruff, J. A., Lacey, E. A., Bentley, G. E., \& Kriegsfeld, L. J. (2013). Effects of social environment on baseline glucocorticoid levels in a communally breeding rodent, the colonial tuco-tuco (Ctenomys sociabilis). Hormones and Behavior, 64, 566-572. https://doi.org/10.1016/j. yhbeh.2013.07.008

Zuur, A. F., leno, E. N., \& Elphick, C. S. (2010). A protocol for data exploration to avoid common statistical problems. Methods in Ecology and Evolution, 1, 3-14. https://doi.org/10.1111/j.2041-210X.2009.00001.x

\section{SUPPORTING INFORMATION}

Additional supporting information may be found online in the Supporting Information section at the end of the article.

How to cite this article: Santicchia F, Dantzer B, van Kesteren F, et al. Stress in biological invasions: Introduced invasive grey squirrels increase physiological stress in native Eurasian red squirrels. J Anim Ecol. 2018;87:1342-1352. https://doi. org/10.1111/1365-2656.12853 